University of Nebraska - Lincoln

DigitalCommons@University of Nebraska-Lincoln

Robert G. Fuller Publications and Presentations Research Papers in Physics and Astronomy

September 2006

\title{
Numerical Computations in US Undergraduate Physics Courses
}

Robert Fuller

rfuller@neb.rr.com

Follow this and additional works at: https://digitalcommons.unl.edu/physicsfuller

Part of the Physics Commons

Fuller, Robert, "Numerical Computations in US Undergraduate Physics Courses" (2006). Robert G. Fuller Publications and Presentations. 43.

https://digitalcommons.unl.edu/physicsfuller/43

This Article is brought to you for free and open access by the Research Papers in Physics and Astronomy at DigitalCommons@University of Nebraska - Lincoln. It has been accepted for inclusion in Robert G. Fuller Publications and Presentations by an authorized administrator of DigitalCommons@University of Nebraska - Lincoln. 


\title{
Numerical Computations in US Undergraduate Physics Courses
}

\author{
A recent study conducted via email and Web surveys gathered responses from physics \\ faculty members across the US about their use of numerical computations in the \\ classroom. Responses showed a strong commitment to computational activities from some \\ physics faculty and a frustration over the lack of such activities from others.
}

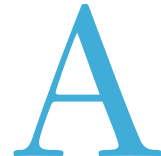
$\mathrm{t}$ the summer American Association of Physics Teachers (AAPT) meeting in Salt Lake City, a heated discussion arose about the state of numerical computations in undergraduate physics courses in the US. It was suggested that a nationwide survey be conducted to find out more exactly what the state of computational physics really is in this country. Norman Chonacky, CiSE's editor in chief, offered the magazine's support in conducting such a study. He proposed the following working definition of computational physics:

\begin{abstract}
"By computation in physics here we mean uses of computing that are intimately connected with content and not its presentation. There seems to be no concurrence on which role(s) are appropriate for computing in physics, but there is a distinction we can draw between computers used for instructional methodologies and computers used for computational physics."
\end{abstract}

We're interested in the latter where, as in calculus,

$1521-9615 / 06 / \$ 20.00$ ๑ 2006 IEEE

Copublished by the IEEE CS and the AIP

ROBERT G. FULLER

University of Nebraska-Lincoln we use computation to derive solutions to problems. The goal of the study is to provide a snapshot of the landscape of computational practices in physics courses and describe some exemplary cases. Hopefully, the articles in this issue help achieve this goal.

\section{The Study Process}

When CiSE magazine commissioned the study in late 2005, Chonacky, Dave Winch of Kalamazoo College, and I decided to conduct a national survey using only electronic communication. We felt that physics faculty members using computers in their courses would be comfortable with such communication to give information about their computer use.

We decided to first issue an open-ended general call for information. Then, we'd use the information we received to look for common elements that merited further inquiry.

We gathered a broad selection of email addresses for the initial call from list servers and lists of participants in new technology workshops offered for physics faculty in the early 1990s. This process gave us addresses for roughly 150 faculty members. We also obtained access to a professionally available list of email addresses for the chairs of 762 physics departments in the US. Ultimately, our total distribution list included roughly 900 physics faculty members.

We personally addressed the first open-ended inquiry, which we started at the end of November 

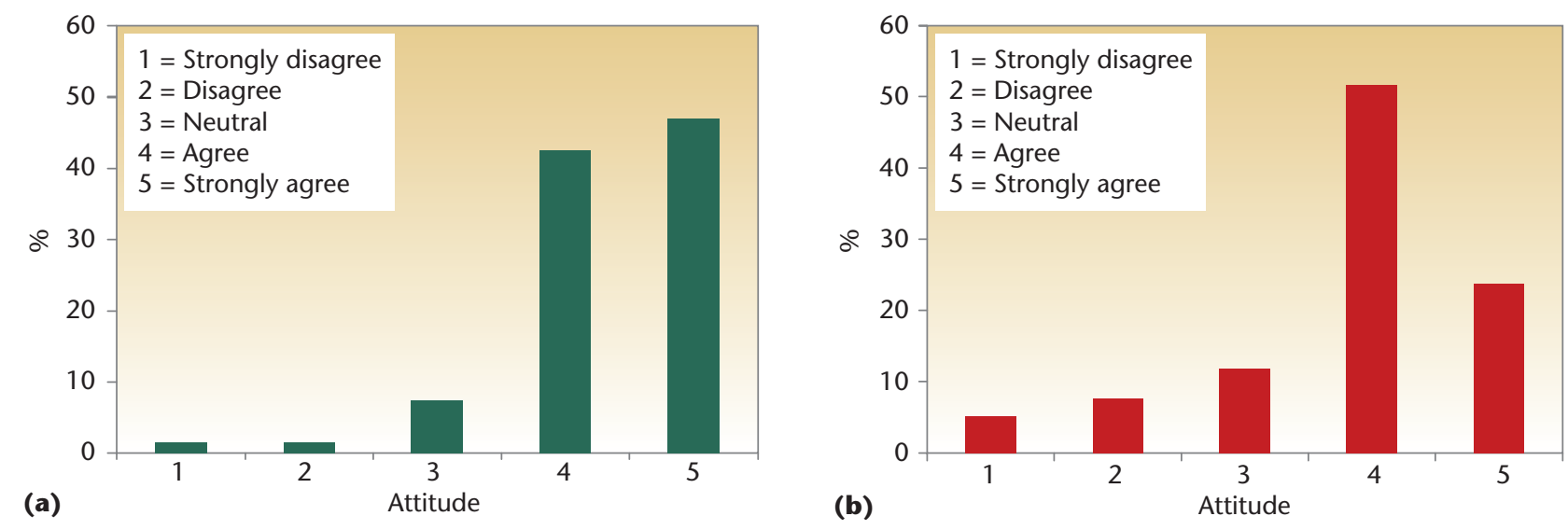

Figure 1. Comparison of responses to assertion 7: "Computed numerical approaches to learning physics principles ought to share the stage with analytic approaches." (a) Early responders and (b) Web-survey-only responders.

2005, to each person on the list. A copy of the cover letter for the inquiry and the call document are available on CiSE's Web site (http://opac.ieeecomputer society.org/opac? year $=2006 \&$ volume $=8 \&$ issue $=5 \&$ acronym=cise). The inquiry generated responses from 135 physics faculty members, ranging from a few words to a few pages. The complete database of these responses is also available on the CiSE Web site.

Winch, Chonacky, and I read and discussed the responses. We then developed a Web survey questionnaire and posted it on the CiSE Web site (you can still view the questionnaire at www.computer. org/portal/pages/cise/techreviews/v8n3/). We personally emailed the questionnaire to all 135 early responders and bulk-mailed it to the chairs of departments from which we'd received no information. The Web survey questionnaire generated additional information from 70 of the early responders and first-time responses from 117 other physics departments. We obtained somewhat unorthodox responses from a few more departments. Hence, a total of 252 physics departments participated in some way in the study.

\section{The Audience Effect}

Whenever you base a survey on responses from volunteers in an audience, you must ask how these responses relate to the entire audience's responses. In this study, the first responses were to an openinquiry letter and provoked a variety of essay responses. We expect that those physics faculty most positively inclined toward using computations in their physics courses would be most likely to respond to the open-inquiry letter. Ample evidence suggests that the department chairs receiving the open-inquiry e-letter forwarded it to a faculty member likely to answer it. Fortunately, 70 of the early responders also responded to the Web survey questionnaire, to which 117 other departments also responded. We decided that the attitudes expressed in assertions 7 and 8 would be a good measure of how well the early responders' attitudes represented the total audience. Figures 1 and 2 show histograms of the frequency of the attitudes expressed by responders to assertions 7 and 8 .

As expected, the early responders are more definite in their positive and negative attitudes about these two assertions, but the total number of agreements to assertion 7 and disagreements to assertion 8 are remarkably similar for the two separate audiences, with 76 to 90 percent agreeing with assertion 7 and 67 to 68 percent disagreeing with assertion 8 . Because of the similarity in the responses of the two audience segments, we decided that an analysis of the complete set of 187 responses to the Web survey questionnaire would best represent the study's quantitative results.

\section{Quantitative Results}

Our quantitative study began with an examination of the attitudes expressed toward the seven assertions in the Web survey. The physics faculty represented in this study pretty strongly support incorporating numerical computational activities in physics courses and consider these kinds of activities to be an important part of the undergraduate physics curriculum.

Figure 3 shows the histograms for the 187 responses to each of the assertions in the Web survey. For all histograms, the attitudes' numerical values are 1 = strongly disagree; 2 = disagree; $3=$ neutral or no opinion; $4=$ agree; and $5=$ strongly agree.

Assertion 7 claims, "Computed numerical approaches to learning physics principles ought to 

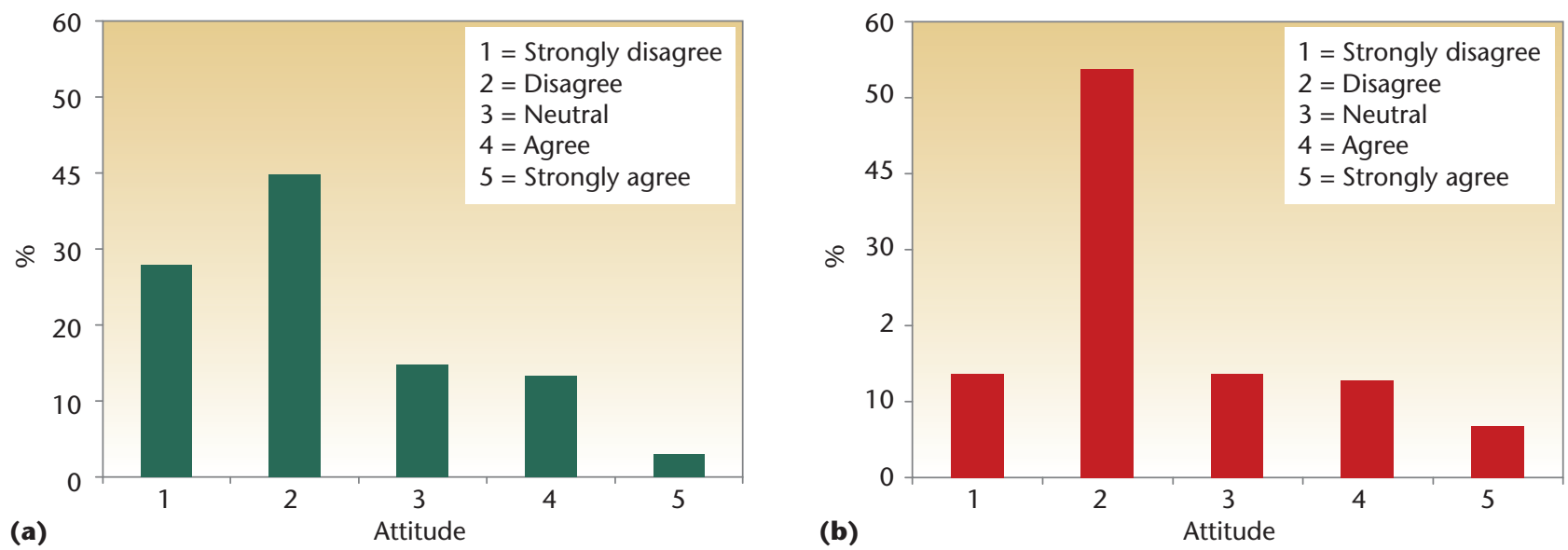

Figure 2. Comparison of responses to assertion 8: "Analytic approaches to learning physics principles are necessary and sufficient for educating physics students." (a) Early responders and (b) Web-survey-only responders.

share the stage with analytic approaches." Almost 50 percent of the responders agree with this assertion and more than 30 percent strongly agree - that is, 80 percent of the physics faculty participating in this study think that numerical approaches have an important role in learning physics principles.

Assertion 8 states, "Analytic approaches to learning physics principles are necessary and sufficient for educating physics students." Almost 50 percent of the responders disagree with this assertion and almost 20 percent strongly disagree-that is, 68 percent of the participating physics faculty think that analytic approaches aren't necessary and sufficient for physics students today.

Assertion 9 claims, "Numerical approaches should be the major emphasis with analytic approaches reserved for statements of principles, that is, as starting points for numerical calculations." Fifty percent of the responders disagree with this assertion and almost 30 percent strongly disagreethat is, 79 percent of the participating physics faculty don't think that numerical approaches should replace analytic approaches.

Assertion 10 is, "Numerical solutions should be used only to illustrate how the analytic solutions can be evaluated to yield actual values in specific cases." Almost 50 percent of the responders disagree with this assertion and almost 20 percent strongly disagree-so, a total of 66 percent of the participating physics faculty don't think that numerical solutions should be reserved to simply evaluate analytic solutions.

Assertion 11 states, "Numerical modeling is too much of a departure from what physics does and should be used only, if at all, where analytic models do not work well." Almost 50 percent of the re- sponders disagree with this assertion and nearly 30 percent strongly disagree-that is, 77 percent of the participating physics faculty don't think that numerical modeling is a significant departure from physicists' important activities.

Assertion 12 claims, "Numerical modeling should be taught to prepare physicists for working in a world which can be modeled only numerically except for the few cases (for example, harmonic oscillator) that we use over and over again." Fifty-two percent of the responders agree with this assertion and 30 percent strongly agree-so, a total of 82 percent of the participating physics faculty think that studying numerical modeling has an important role in the work and preparation of physicists for today's world.

Taken as a whole, the attitudes of the physicists in this study show a strong agreement about the role of numerical computations using computers in physicists' lives and course preparation. Survey participants see computers as an essential partner in what physicists do today, in both research and education.

Beyond this strong commitment to computational physics, however, the responses to assertion 13 and question 2 show some areas of concern for the computational physics community.

Assertion 13 states, "Numerical modeling is a much demanded skill in other sciences and engineering such that physics departments ought to take it as a service function to teach such skills in our service courses." Thirty percent of the responders are uncertain about this assertion and an additional 19 percent disagree with it, an almost 50/50 split. Physics courses' service role of teaching students computational skills isn't a clear priority to the part of the physics educational community participating in this study. Encourag- 


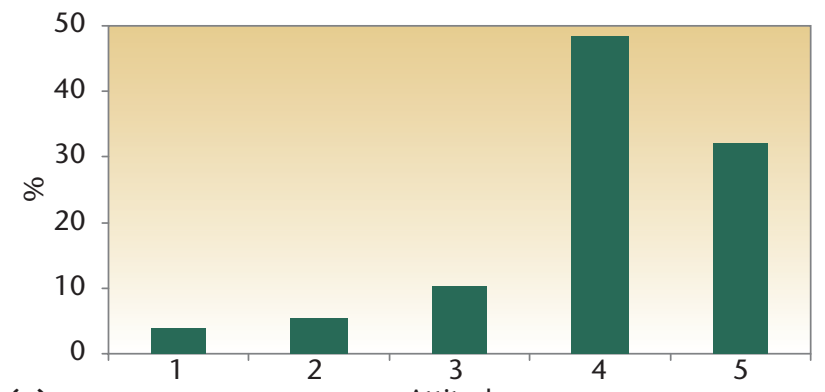

(a)

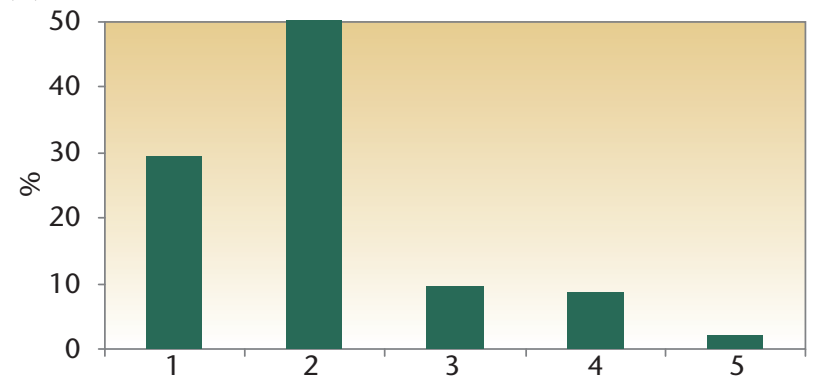

(c)

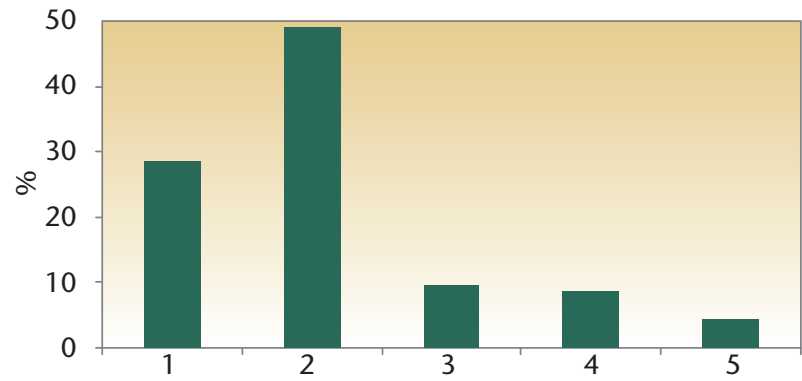

(e)

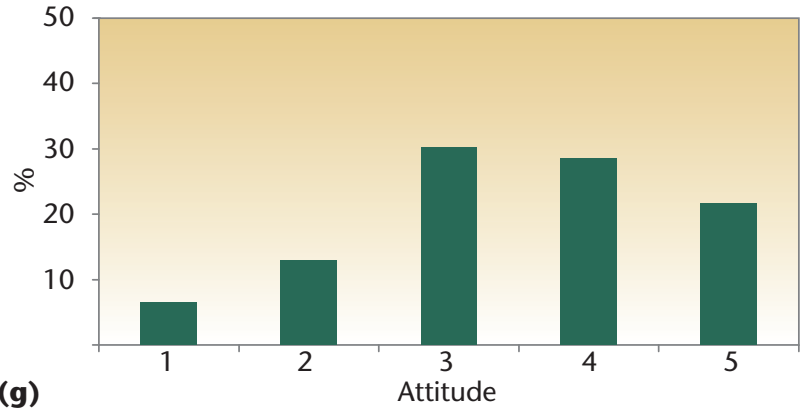

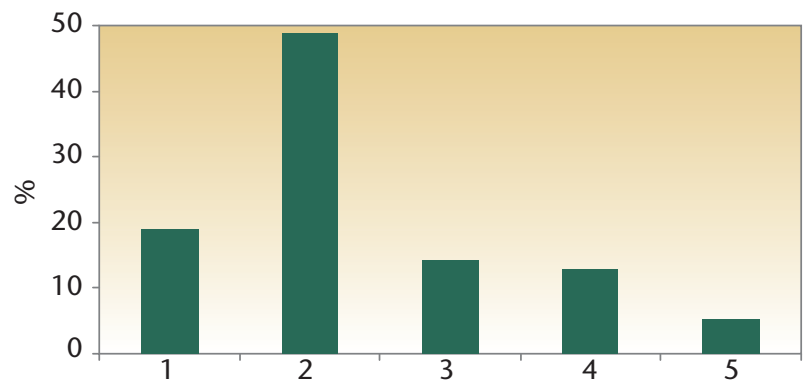

(b)
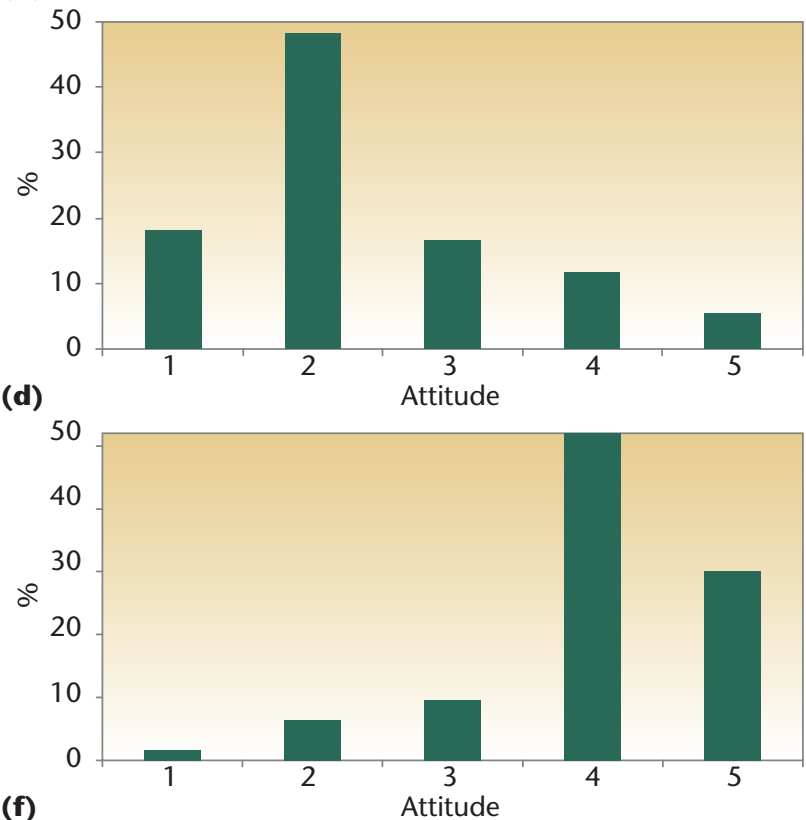

$1=$ Strongly disagree

$2=$ Disagree

$3=$ Neutral

$4=$ Agree

$5=$ Strongly agree

Figure 3. Responses to assertions in the Web survey. Note the differences between (a) assertion 7, (b) assertion 8, (c) assertion 9, (d) assertion 10, (e) assertion 11, (f) assertion 12, and (g) assertion 13. For all histograms, the attitudes' numerical values are 1 = strongly disagree; 2 = disagree; $3=$ neutral or no opinion; 4 = agree; and $5=$ strongly agree.

ing physics departments to perform what the computational physics community sees as an important service activity will require some additional outreach and persuasion.

The responses to question 2-"About what percentage of [physics faculty] require students to use \{numerical, computer-based\} computations in their courses as a part of the course grade?"- are another warning sign. We divided the responses to this question into percentage bins, with 20 percent being the bin's width. In the lowest bin are departments with 20 percent or fewer of the faculty requiring students to do computational physics tasks as part of their grade; in the highest bin are departments with 80 percent or more of the faculty with the same requirement.

As Figure 4 shows, the results indicate that in 39 percent of the physics departments responding to 


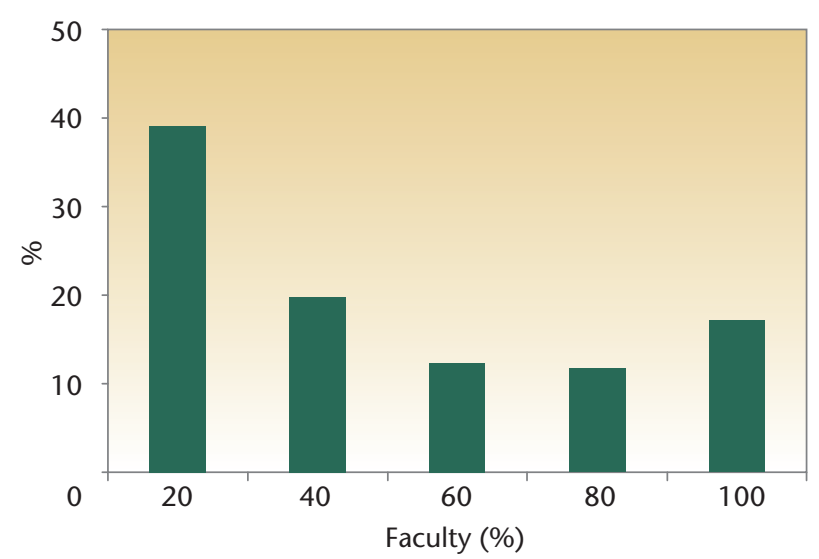

Figure 4. Results for question 2 of the Web survey. As the graph indicates, fewer than 20 percent of the physics faculty responding to our survey include computer computations in their grading.

this survey, fewer than 20 percent of the faculty include computer computations in their course grades. Those of us who have taught college students know that they value those aspects of a physics course that we include in the course grade. If we believe that writing technical English is a valuable skill for physics students, we must ask them to write something technical that we can grade. Similarly, if computational skills using computers are an essential aspect of being a physicist in the 21 st century, physics faculty members should include that activity as a part of students' grade. There's a disconnect here between physicists' attitudes toward the assertions and their actual performance in the classroom. A qualitative examination of the written responses might suggest what we need to do next.

\section{Qualitative Results}

It seems especially appropriate to begin this section with a quote from Alfred Bork-the guru of the uses of computers in physics education more than 20 years ago. Bork is primarily remembered for his interest in the educational uses of computers in the broadest sense, but he also led numerous workshops at AAPT meetings on such topics as how the computational power of computers ought to change our physics courses. He also published a treatise on using numerical methods to teach Newton's laws of motion. If you're unfamiliar with Bork's writings, you should read his Millikan lecture for $1978^{1}$ as well as some of his other writings. ${ }^{2-4}$ Bork wrote in 1984,

"We should not seek the 'best' way of using the computer in learning. The computer can be used in many different ways to aid many different as- pects of the learning process. None of these should be eliminated at the present time, when our experience with first rate use of the computer is so limited." 5

Those who participated in Bork's computer workshops at AAPT meetings have heard him say many times, "Let a thousand flowers bloom."

The flowers have certainly been blooming in computational physics! The poster session at the AAPT meeting and other articles in this issue of CiSE describe ongoing efforts at institutions such as Austin Peay State University, Bradley University, Davidson University, Henderson State University, Illinois State University, Kenyon College, Lawrence University, North Carolina State University, Oregon State University, Richard Stockton College of New Jersey, Rider University, University of California, Irvine, University of Cincinnati, University of Saint Thomas, and Whittier College.

The departmental commitments at some institutions are impressive:

"...we have a proficiency requirement in four areas of computing: 1) programming; satisfied by taking the appropriate computer science course, or demonstrating proficiency by writing programs during the year-long senior thesis project required of all seniors. 2) scientific word processing; satisfied by turning in an electronic version of the senior thesis with typeset equations and embedded figures. 3) Web resources; satisfied by attending an introductory lecture from the librarian and then using the Web-based research tools during the senior thesis project. 4) symbolic mathematics; satisfied by assignments within the standard curriculum that use Maple, Mathematica, Matlab." — responder from College of William and Mary

Meanwhile, at the other end of the spectrum are various colleges and universities, whose names I will leave out, but that had the following comments:

"I think our integration of computation in our physics courses is quite minimal at this point (really too minimal)."

"While [we] might be listed as a 'laptop' college, in practical terms it is nothing of the sort. We are just now placing computers in the physics labs here, so to my knowledge nothing computationally has been done here in the department."

"Let me start by explaining that we do not have 
any computational activities embedded formally in our physics courses. Some professors, though, do include some use of software and simulations in their courses."

The total response showed that roughly 55 percent of departments have some kind of separate computational physics course, offered at various levels_-from freshmen to senior-with a wide variety of prerequisites-from none to vector calculus. A majority of the other departments (roughly 29 percent of the total) have made significant efforts to embed computational activities in their traditional physics courses. There are strong advocates for both types of departmental responses to computers' existence. The remaining departments (roughly 16 percent of the total) aren't doing much.

Just as departments are offering a wide variety of computational physics courses, faculty are using a wide variety of textbooks in these courses, with no one textbook seeming to dominate. Survey respondents mentioned textbooks by Alejandro Garcia, ${ }^{6}$ Nick Giordano and Hisao Nakanshi, ${ }^{7}$ and Harvey Gould, Jan Tobochnik, and Wolfgang Christian $^{8}$ most often, followed closely by in-house notes. Departments that have made curriculum changes to include computations in their physics courses mentioned textbooks by David Cook ${ }^{9}$ and Ruth Chabay and Bruce Sherwood. ${ }^{10}$

The wide variety of software packages used in physics departments matches the variety of uses of computations. Mathematica, Matlab, and Maple predominate in physics departments. Many departments ask their students to use programming languages. Fortran is still a strong language in physics departments, and $\mathrm{C}++$ and $\mathrm{C}$ are the current choices in computer courses with many physics students.

Computers are ubiquitous in physics laboratories. Data-acquisition software and hardware from Vernier and Pasco are widespread. LabView software is also popular, and spreadsheets are used almost universally. Many students now come to college with an excellent working knowledge of spreadsheets.

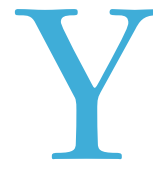
ou can't read the items in this study's database without catching the sense of excitement and commitment of physics faculty members involved in developing the use of computer computations in physics courses. This is clearly one of the most exciting changes to occur in the undergraduate physics curriculum since the 1950s. The widespread use of inhouse notes speaks to the variety of ideas that these faculty members have about what needs to be taught and how to teach it in computational physics classes.

This study found approximately 150 physics departments that actively incorporate computational activities into their undergraduate curriculum. But what about the more than 600 other physics departments? Most of them-roughly 500 — aren't included in this study. Perhaps a few of the more poignant entries will guide us into the future:

"I have been disappointed through the years at how little computer-based problem-solving seems to have been integrated into physics courses. Perhaps there is more going on than I think but it seems that most courses have changed very little."

"My faculty is considering creating a computational physics course because of the demand for such skills our students will face when they graduate. We have had input from some of our alumni, pointing out the need for such training."

"I'd like to work more computation into my classes, but haven't made it a regular part of teaching."

Physics faculty members are expressing a desire to do more with computations in their physics courses. How will the computational physics educational community respond?

\section{References}

1. A. Bork, "Interactive Learning," Am. J. Physics, vol. 47, no. 1, 1979, pp. 5-10.

2. A.M. Bork, Computer Assisted Learning in Physics Education, Pergamon Press, 1980

3. A.M. Bork, Learning With Computers, Digital Press, 1981.

4. A.M. Bork, Personal Computers for Education, HarperCollins, 1985.

5. A. Bork, "Computer Futures for Education," Creative Computing, vol. 10, no. 11, 1984, pp. 178-180.

6. A.L. Garcia, Numerical Methods for Physics, 2nd ed., Prentice Hall, 2000.

7. N.J. Giordano and H. Nakanishi, Computational Physics, 2nd ed., Prentice Hall, 2006.

8. H. Gould, J. Tobochnik, and W. Christian, An Introduction to Computer Simulation Methods, 3rd ed., Addison-Wesley, 2006.

9. D.M. Cook, Computation and Problem Solving in Undergraduate Physics, Dept. of Physics, Lawrence Univ., 2006.

10. R. Chabay and B. Sherwood, Matter and Interactions, John Wiley \& Sons, 2006.

Robert G. Fuller is a professor emeritus of physics at the University of Nebraska-Lincoln. In 1980, he served as president of the American Association of Physics Teachers. Fuller has a PhD in physics from the University of Illinois. Contact himat rfuller@neb.rr.com. 